\title{
Incorporating nano graphene oxide to poly-methyl methacrylate; antibacterial effect and thermal expansion.
}

\author{
Reem Gamal $^{1 *}$, Yasser F. Gomaa ${ }^{1}$, Ashraf M. Said ${ }^{2}$ \\ ${ }^{1}$ Department of Biomaterials, Faculty of Dentistry, Minia University, 61519 Minia, Egypt \\ ${ }^{2}$ Department of Bio-Medical Engineering, Faculty of Engineering, Minia University, 61519 Minia, Egypt \\ * Correspondence: dr.reem.gamal@ @u.edu.eg; Tel: +201062477286; Fax: +20 862347767
}

Article information
Received: 3 July 2019
Revised: 10 July 2019
Accepted: 10 July 2019
Key words
Graphene oxide
PMMA
Streptococcus Mutans
MIC
Coefficient of thermal expansion

\begin{abstract}
Aim: This in vitro study was performed to evaluate antibacterial effect and thermal expansion of commercial available poly-methyl methacrylate (PMMA) incorporated by nano graphene oxide (GO) in different concentration.

Method: Nano graphene oxide in five concentrations $0 \%, 0.05 \%, 0.1 \%, 0.15 \%$ and $1 \%$ by weight was incorporated to PMMA to form groups I-V respectively. To evaluate the antibacterial effect against Streptococcus Mutans, minimal inhibitory concentration (MIC) for GO dispersion was done and agar well diffusion test for groups I-IV was done. Thermal expansion was assessed through measuring the linear coefficient of thermal expansion.

Results: For antibacterial effect, all concentrations tested for MIC showed inhibition zone varied from 0.5 to $2 \mathrm{~mm}$ in diameter. All tested groups evaluated by agar well diffusion method showed no inhibition zones except for group II. Significant reduction in coefficient of thermal expansion was showed by increasing GO concentration.

Conclusions: Incorporation of GO in to PMMA at concentration of $0.5 \%$ can inhibit the growth of Streptococcus Mutans. There is an inverse relation between the concentrations of GO and the coefficient of thermal expansion.
\end{abstract}

\section{Introduction}

Poly-methyl methacrylate (PMMA) is a widely used polymer in medical and dental fields since 1937 [1-3]. It is used as bone cement, denture teeth, denture base, liners, obturators, temporary veneers, special trays and temporary crowns [4]. It has three types according to its activation method, chemical cure, heat cure and dual cure. [5] Chemical cure type composed of powder and liquid. The powder is PMMA combined by initiator and the liquid is methyl methacrylate monomer combined by activator $[5,6]$. Upon mixing the powder to the liquid activators immediately start the free radical polymerization reaction by breakage of the initiator releasing the free radicals which initiate the reaction, then the reaction propagates and the polymer set $[5,6]$.

PMMA has many useful properties as adequate mechanical properties, low cost, easily manipulation and easy repair [7-8]. However, it has some draw backs such having inherent surface properties enhances the microbial growth leading to several oral diseases such as carries or oral stomatitis [9-11]. Also it has excessive thermal expansion [5].

According to world health organization WHO the etiology of dental caries is the formation of microbial biofilm on the tooth surface which able to converts the free sugars contained in foods and drinks into acids. These acids can dissolve tooth enamel and dentin over time. Destroying tooth structures resulting in development of cavities and pain which impacts on oral health and in the advanced stage, tooth loss and systemic infection [12]. Most of diagnostic, preventive and therapeutic methods of dental carries have been targeted toward these microbial biofilm $[11,13]$.

Thermal expansion and contraction is an essential property for material used in restorative dentistry because oral cavity and tooth structure are subjected to wide range of temperature fluctuations [14]. Linear coefficient of thermal expansion $(\alpha)$ is normally used to describe the fractional dimensional changes of a substance in response to thermal stimuli [14,15]. Thermal stresses developed at the interface between PMMA and other materials as tooth structure, artificial teeth..etc. when there is a mismatch of $\alpha[5,14]$ lead to leakage, percolation, damage and fracture limiting the usage of PMMA [16].

For enhancing the properties of PMMA, many attempts had been done. One of these attempts is nanofillers incorporation to PMMA matrix. Nano graphene oxide (GO) is two-dimensional carbon nanomaterial consisting of a layer of single atom thick $s p^{2}$ bonded carbon atoms. It has a closely packed hexagonal honey comb structure that contains functional groups as epoxy, hydroxyl, carbonyl, and carboxylic on surface and at edges. [3, 17] Graphene oxide has unique properties as antimicrobial effect, high physical and mechanical properties $[17,18]$. The antibacterial effect of GO was attributed to several physical and chemical mechanisms. Two physical mechanisms were available, one of these mechanisms was carried out by the sharp edges of GO which is able to cut through the cell walls of the bacteria causing leakage of the intracellular matrix and 
bacterial death. The second one is carried out by wrapping effect of larger GO sheets to the bacterial cells preventing there proliferation. The chemical mechanism is carried out by induction the production of reactive oxygen specious that oxidize fatty acids in the bacterial cell wall leading to its disintegration and cell death [19-22]. The concentration and size of GO particles determine the mechanism of action that inhibits the bacteria [22].

Few studies were found discussing the effect of incorporation of graphene oxide to chemical cure poly-methyl methacrylate on antibacterial effect against Streptococcus mutans (SM) and linear coefficient of thermal expansion. Therefor this study was conducted to evaluate the effect of adding different concentrations of GO into PMMA on these properties. The null hypotheses that to be tested were addition of low concentrations of GO to PMMA have no effect on SM and linear coefficient of thermal expansion also GO dispersion couldn't inhibit SM.

\section{Materials and methods}

Nano graphene oxide manufactured by improved Hummer's method supplied from Materials Science and Nanotechnology Department, Faculty of Postgraduate Studies for Advanced Sciences, Beni-Suef University and Self-cure PMMA supplied from Acrostone Dental Manufacturer, Egypt was used in this study.

Nano graphene oxide were incorporated to PMMA powder in concentrations of $0 \%, 0.05 \%, 0.1 \%, 0.15 \%$ and $1 \%$ by weight to form groups I-V respectively regarding to Morimune et.al 2012 [23], Pham et.al 2012 [24] and Kee et.al 2017 [25] methods.

\subsection{Antibacterial test}

All procedures were carried out under aseptic conditions. All medias used in this study were prepared as manufacturer instruction. For inoculum preparation, Streptococcus Mutans (SM) EMCC $1815^{\mathrm{T}}$ supplied from Microbiological Resources Centre (MERCIN), Faculty of Agriculture, Ain Shams University in Lyophilized form was used in this study. Hydrating fluid was added to lyophilized microorganism and shacked well. Then swab was heavily saturated by the hydrated suspension and gently rolled over freshly prepared blood agar plate to inoculate it by SM. The agar plate was incubated (Precision incubator, Ohio, USA) at $37 \pm 1{ }^{\circ} \mathrm{C}$ for $24 \mathrm{~h}$ in candle jar. Three discrete representative colonies were inoculated into $2 \mathrm{ml}$ sterile saline and diluted to obtain turbidity equal to 0.5 McFarland turbidity standard solution which prepared according to Clinical and Laboratory Standards Institute CLSI 2012 [26] to form inoculum. To facilitate the compression between 0.5 McFarland turbidity tube and the inoculum tube Wickerham card was used.

\subsubsection{Minimal inhibitory Concentration (MIC)}

For preparation of $1 \%$ wt GO dispersion one gram of GO powder was weighted by digital balance (Electronic balance ATY224, Kyoto, Japan with $0.0001 \mathrm{~g}$ accuracy) and added to 99 $\mathrm{ml}$ deionized water in tightly sealed jar and sonicated for $1 \mathrm{hr}$ by dental ultrasonic cleaner (CD4820, Henan, China) at $170 \mathrm{~W}$ power and $42 \mathrm{KHz}$ frequency. The MIC of GO dispersion was measured via macro broth dilution and agar well diffusion methods these methods were done regarding to CLSI 2012 [26] and Deyab et. al 2018 [27]

For macro broth dilution methods, serial double fold dilutions were made starting from $1 \%$ GO dispersion. Test tubes were labeled from 1 to 5 with tube no. 1 was contained 2 $\mathrm{ml}$ of $1 \%$ wt GO dispersion. Using a micropipette, $1 \mathrm{ml}$ of Brain heart infusion broth (BHIB) was withdrawn and dispensed in each test tube from no. 2 to 5 . Using another micropipette tip, $1 \mathrm{ml}$ of the stock was withdrawn from tube no.1, dispensed in tube no. 2 and mixed thoroughly with the $1 \mathrm{ml}$ of BHIB. One $\mathrm{ml}$ of the mixture in tube no. 2 was then withdrawn, dispensed in tube no. 3 and mixed thoroughly with the $1 \mathrm{ml}$ BHIB. The same steps were repeated for the next tubes. Finally, each tube from no. 2 to no. 4 contained $1 \mathrm{ml}$ whereas tube no. 5 contained $2 \mathrm{ml}$ of suspension in serial dilutions. $1 \mathrm{ml}$ of this tube was withdrawn. Another dilution was made to produce three other concentrations by mixing $1 \mathrm{ml}$ of the $1 \%$ GO dispersion to $6.5 \mathrm{ml}$ BHIB, $1 \mathrm{ml}$ of the $1 \%$ GO dispersion to $9 \mathrm{ml}$ BHIB and $1 \mathrm{ml}$ of the $1 \%$ GO dispersion to $19 \mathrm{ml}$ BHIB. $1 \mathrm{ml}$ from each dilution was put in a tube and labeled from 6 to 8 respectively. The concentration in tubes from 1 to 8 were $1 \%, 0.5 \%, 0.25 \%$, $0.125 \%, 0.06 \%, 0.15 \%, 0.1 \%$ and $0.05 \%$ respectively. Twenty microliter of the inoculum was inserted in each tube and mixed well. Then all tubes were closed and incubated at $37^{\circ} \mathrm{C} \pm 1{ }^{\circ} \mathrm{C}$ for $24 \mathrm{hr}$. The MIC was considered the lowest concentration of GO that completely inhibits growth of the organism in tubes. All tubes showed turbidity which might be due to bacterial growth or from the GO dispersion itself so $5 \mu \mathrm{l}$ from each tube cultured on sterile blood agar plate and incubated in candle jar for another $24 \mathrm{hr}$ to confirm and verify the results.

For Agar diffusion method, serial double fold dilutions were made for the $1 \% \mathrm{GO}$ dispersion in the same method mentioned before using deionized water instead of BHIB. Another tube containing $1 \mathrm{ml}$ of deionized water was prepared and considered as a negative control. Freshly prepared plastic blood agar plates $(9 \mathrm{~cm}$ in diameter) containing $2 \mathrm{~mm}$ agar thickness were seeded by saturated swap from inoculum and kept at refrigerator for $2 \mathrm{hr}$ in order to allow a good diffusion of the tested compounds into the agar medium. Using the back sterile micropipette tip, six holes $(7 \mathrm{ml}$ in diameter) were punched in the first culture plate and four in the other plate. One of the holes which punched in each plate was filled with $20 \mu \mathrm{l}$ sterile deionized water as a control. For the first plate dilutions $1-5$ were tested ( $20 \mu \mathrm{l}$ from each dilution in holes). In the second plate dilutions from 6-8 were tested. The plates were then incubated in candle gar at $37 \pm 1{ }^{\circ} \mathrm{C}$ for $24 \mathrm{hr}$. The distance of the inhibition zones around each hole was measured in 
millimeters using digital caliper (RS PRO, 841-2518, Northants, $\mathrm{UK})$ at three different points, and the mean was recorded.

\subsubsection{Antibacterial activity assessment}

The agar well diffusion test was used to evaluate the antibacterial activity of PMMA incorporated by GO. Ten freshly prepared plastic blood agar plates were seeded by SM. Fifty discs shaped specimens (10 for each group) were prepared by mixing the powder of groups I-V and monomer were mixed as manufacturer instruction and poured in specially constructed split Teflon molds $15 \pm 0.1 \mathrm{~mm}$ diameter and $1 \pm 0.1 \mathrm{~mm}$. One specimen from each group was placed in the agar plate previously seeded with SM by sterile forceps. A distance of at least $1.5 \mathrm{~cm}$ between each disc was made.

Then the plates were incubated at $37{ }^{\circ} \mathrm{C} \pm 2{ }^{\circ} \mathrm{C}$ in candle jar for $24 \mathrm{hr}$. After that the diameters of the circular inhibition zones produced around the specimens were measured in millimeters with a digital caliper at three different points, and the mean was recorded.

\subsection{Linear coefficient of thermal expansion and contraction (a)}

Groups I-IV were tested for $\alpha$. A total of 80 specimens (20 for each group) were formed in a specially constructed bar shaped steal molds $(65 \pm 0.1 \mathrm{~mm}$ length, $10 \pm 0.1 \mathrm{~mm}$ width and $3 \pm 0.1 \mathrm{~mm}$ height $)$ with three pyramidal shaped ridges $(1 \pm 0.1$ mm height) on the widest surface. Ridges were named A, B and C, distance between A-B and B-C was 20mm each (Figure 1). Specimens of GO/PMMA composite were prepared as mentioned before. Each specimen had three V shaped groves A, $\mathrm{B}$ and $\mathrm{C}$ on its widest surface (Figure 2).

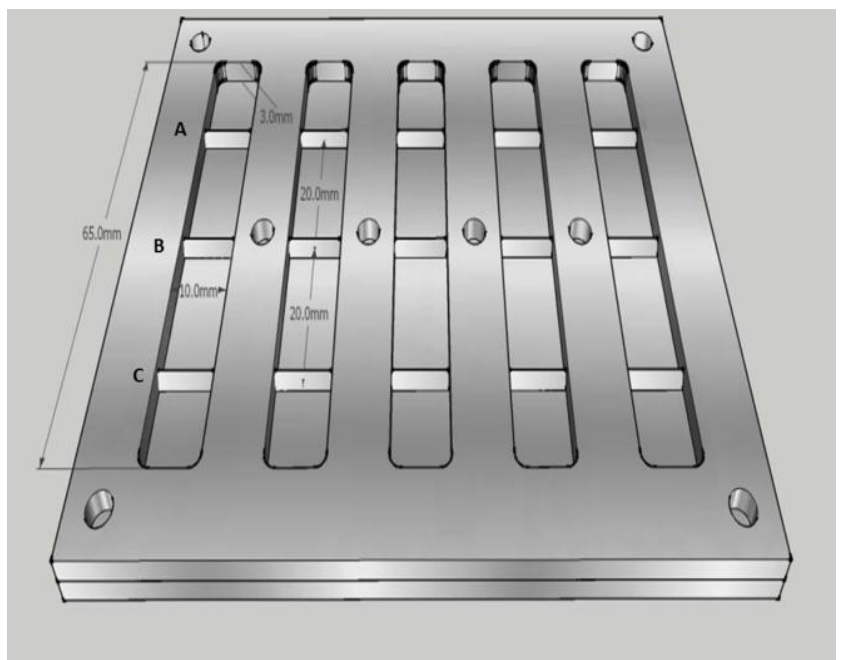

Figure 1: Schematic diagram for molds (a) bar shaped steal molds $(65 \times 10 \times 3 \mathrm{~mm})$ with three pyramidal shaped ridges(A, B and $\mathrm{C}$ ) on the widest dimension surface distance between $\mathrm{A}-\mathrm{B}$ and $\mathrm{B}-\mathrm{C}$ was $20 \mathrm{~mm}$.

Specimens were labeled, stored in water for 7 days and heated in water bath at $70{ }^{\circ} \mathrm{C}$ for 30 minutes. Then they were bench cooled to room temperature. The distances between the grooves (initial length $\left(\mathrm{L}_{\mathrm{i}}\right)$ ) for each specimen were measured by electronic digital caliper at $25{ }^{\circ} \mathrm{C}$ (initial temperature ${ }^{\circ} \mathrm{C}_{\mathrm{i}}$ ).

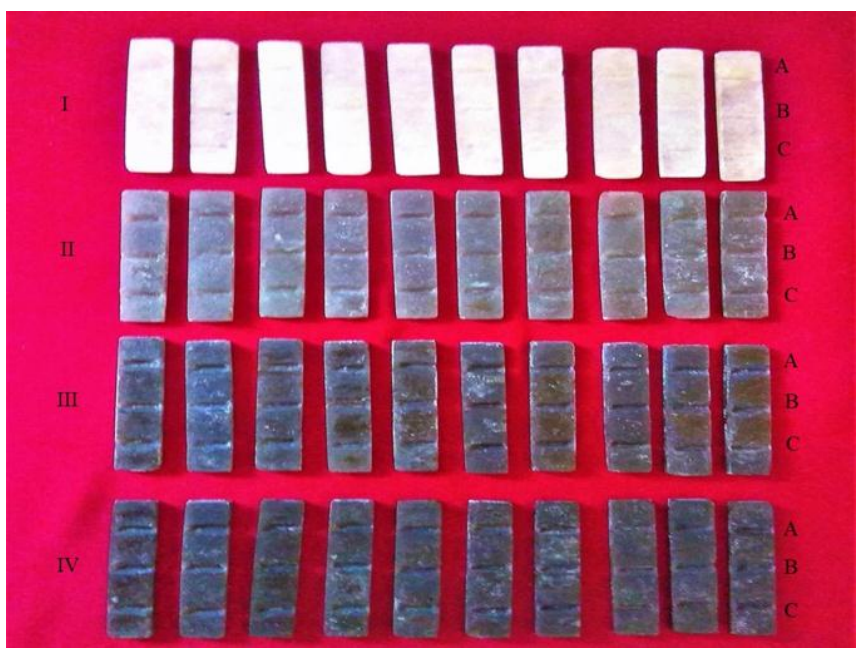

Figure 2: Specimens of different groups with three $\mathrm{V}$ shaped groves $\mathrm{A}, \mathrm{B}$ and $\mathrm{C}$ on their widest surface

In order to gradually heat the specimens, a custom made machine was designed especially for this purpose. This machine comprised of various entities that were connected to each other. There were heating device with stainless steel container and plastic mesh fixed in it, temperature control unit, heat sensor type $\mathrm{K}$ and $220 \mathrm{~V}$ relay. The specimen were inserted above the mesh in the water bath and the machine was adjusted to heat the water bath in five steps $\left(5^{\circ} \mathrm{C} / 5\right.$ minutes $)$ and fix the temperature to a final temperature $\left(\mathrm{C}_{\mathrm{f}}\right) 50{ }^{\circ} \mathrm{C}$ till measuring was done. Distances between A-B and B-C for each specimen were measured again to achieve final length $\left(\mathrm{L}_{\mathrm{f}}\right)$. The linear coefficient of thermal expansion and contraction was calculated using the following equation:-

$$
\alpha=\frac{\left(\mathrm{L}_{\mathrm{f}}-\mathrm{L}_{\mathrm{i}}\right)}{\mathrm{L}_{\mathrm{i}} \times\left({ }^{\circ} \mathrm{C}_{\mathrm{f}}-{ }^{\circ} \mathrm{C}_{\mathrm{i}}\right)}
$$

\subsection{Statistical analysis:}

Data was statistically analyzed and significance between groups was calculated using SPSS 25.0 for Windows (SPSS Inc., Chicago, IL, USA). A value of $\mathrm{p}<0.05$ was considered significant.

\section{Results}

For MIC by macro broth dilution all tubes show turbidity, also the entire samples cultured from the tubes showed bacterial growth except for $1 \% \mathrm{GO}$ suspension concentration. For MIC by agar well diffusion method all the concentrations showed inhibition zone in varied diameter for groups $1 \%, 0.5 \%$ and $0.25 \%$ the zone was $0.5 \mathrm{~mm}$. For other concentrations $0.125 \%$, $0.06 \%, 0.15 \%, 0.1 \%$ and $0.05 \%$ the zone was $2 \mathrm{~mm}$. For the control deionized water there is no inhibition zone. For antibacterial assessment via agar well diffusion method all tested samples showed no inhibition zone except for concentration $0.05(7.76 \pm 1.41) \mathrm{mm}$. For $\alpha$ test Group I 
showed the highest statistically significant means (248.06 \pm $87.61) /{ }^{\circ} \mathrm{C}$ PPM to groups II $(161.38 \pm 64.19)$, III $(154.99 \pm$ $65.02)$ and IV $(138.33 \pm 71.61)$ and the lowest mean was for group IV. The means of $\alpha$ in $/{ }^{\circ} \mathrm{C}$ PPM for different groups are represented in (Figure3).

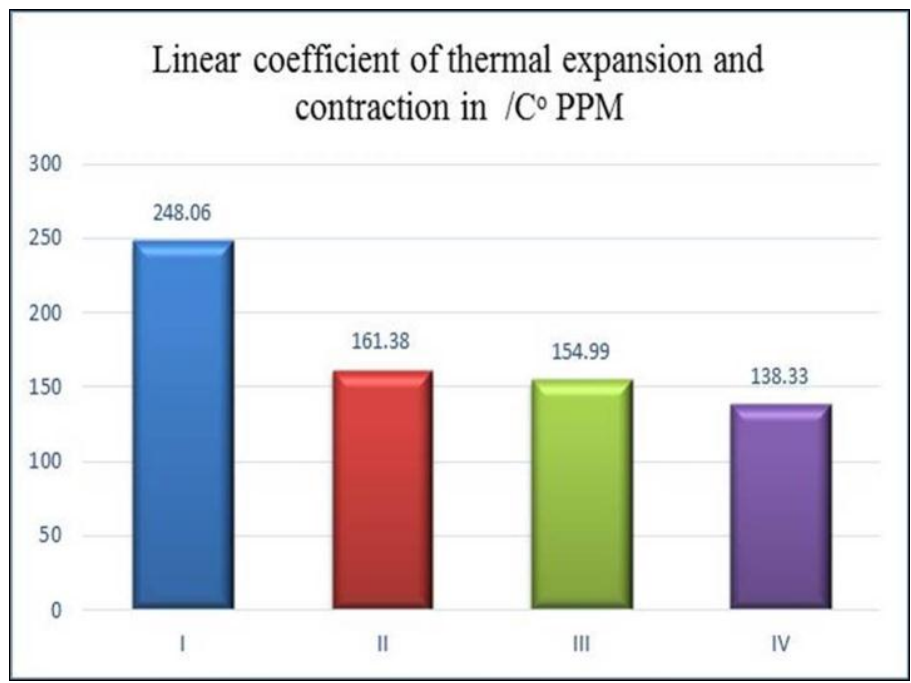

Figure 3: Column chart show means for $\alpha$ in $/{ }^{\circ} \mathrm{C}$ PPM of different tested groups.

\section{Discussion}

This study was conducted to find a way to improve antibacterial behavior of PMMA and $\alpha$ by incorporation of GO. Nano graphene oxide was selected for its known antimicrobial and highly physical properties [3, 28-31]. Chemical cure PMMA was selected to avoid thermal damage to the GO during other curing methods [10]. Streptococcus mutans was targeted in this study as it is one of the basic bacterial types that are able to form cariogenic plaque biofilms [32-34]. Testing of MIC for GO dispersion was done aiming to predict the optimal concentration of GO to be used with PMMA to produce antibacterial effect. MIC is a low-cost and rapid method that requires small amounts of microbial suspension and culture media and provides reproducible results [35].

For macro broth dilution all tubes showed turbidity which might be due to GO dispersion itself or bacterial growth. For confirmation of these results $5 \mu \mathrm{l}$ from each tube was cultured on sterile blood agar plate for another $24 \mathrm{hr}$. All cultures showed bacterial growth on the top of the suspension confirming bacterial growth in all dilution except for $1 \%$ GO. This explained by massive aggregation and precipitation of GO when contact with cations as $\mathrm{Na}^{+}$and other composition in BHIB lead to massive reduction in the surface area of the nano particle contact to the bacteria [36]. This didn't happened in $1 \%$ GO because it was dispersed in deionized water. For MIC measured by agar well diffusion methods all concentrations showed inhibition zone varied regarding to the diffusion ability of each dilution in blood agar which depended on the solubility of GO. The difference in MIC results between the two methods can referred to the difference in type of growth medias and the incubation time [37].
For antibacterial assessment of PMMA incorporated by GO only group II ( $0.05 \%$ concentration) showed inhibition zone and theses may be referred to ability of GO to release from the polymer and diffuse into the agar in this concentration. In higher concentrations no inhibition zone appeared this can be attributed to trapping of GO in the polymer which may be due to its aggregation in these concentrations or its tightly bonding to PMMA matrix.

The MIC of GO dispersion showed results contravenes with antibacterial assessment of PMMA incorporated by GO and these results were in agreement to previous studies [38, 39]. This was explained by ability of GO dispersion to wrap the bacterial cells which was less durable mechanism when GO impeded in the polymer matrix [38, 39].

The antibacterial test results may be contravened with other studies. This contravened explained by difference in concentration, shape, size, surface functionalization of GO, incubation time as well as the characteristics properties of bacteria used in the tests $[22,39,40]$.

High $\alpha$ of PMMA limits its uses intraoral and so improvement of this property is essential. In this study specimens were stored in water for 7 days and heated in water bath at $70{ }^{\circ} \mathrm{C}$ then bench cooled to room temperature to ensure full dimensional change via polymerization shrinkage and water sorption before performing the test. A gradual rate of heating was done for obtaining a uniform heat distribution in the specimens to avoid thermal stresses and obtain uniform expansion. Thermal expansion of a material is due to increase the vibrational motion of atoms and molecules, increasing bond distances leads to expansion [5]. The improvement of $\alpha$ significantly with increasing GO concentration can explain by the interaction between nanofillers and polymer matrix which limited the molecular mobility [41]

\section{Conclusions}

This study focused on assessment of the effect of addition of GO in to PMMA on antibacterial behavior against SM and linear coefficient of thermal expansion. In this study the following findings were concluded; GO water dispersion has antibacterial effect on SM. Incorporating of GO in concentration of $0.05 \%$ to PMMA also had antibacterial effect on SM. There is an inverse relation between the concentrations of GO and the coefficient of thermal expansion. These finding were extremely useful in dental applications as obturators, liners and temporary crown.

Funding:- The authors received no specific funding for this work

\section{References}

[1] Alamgir M, Tiwari SK, Mallick A, Nayak G, editors. Graphene oxide and TiO2 based PMMA nanocomposites for dental applications: A comprehensive study of the mechanical properties. IOP Conference Series: Materials Science and Engineering; 2018: IOP Publishing. 
[2] Sa AN, Tb JK, Mc B, Hd H, Se H. Recent Advances and Future Perspectives for Reinforcement of Poly (methyl methacrylate) Denture Base Materials: A Literature. Journal of Dental Biomaterials. 2018;5(1):1.

[3] Kausar A. Poly (methyl methacrylate) nanocomposite reinforced with graphene, graphene oxide, and graphite: a review. Polymer-Plastics Technology and Materials. 2019;58(8):821-42.

[4] Rashahmadi S, Hasanzadeh R, Mosalman S. Improving the mechanical properties of poly methyl methacrylate nanocomposites for dentistry applications reinforced with different nanoparticles. Polymer-Plastics Technology and Engineering. 2017;56(16):1730-40.

[5] Anusavice KJ, Shen C, Rawls HR. Phillips' science of dental materials: Elsevier Health Sciences; 2012.

[6] Tahir N, Moeen F, Saeed MHB. Effect of Variations in Post-set Temperature and Monomer Concentration on Self-cure Acrylic Surface Candidal Growth: An In-vitro Study. American Journal of Biomedical Research. 2015;3(3):45-52

[7] Tom TN, Uthappa M, Sunny K, Begum F, Nautiyal M, Tamore S. Provisional restorations: An overview of materials used. Journal of Advanced Clinical and Research Insights. 2016;3(6):212-4.

[8] Ghaffari T, Hamedirad F, Ezzati B. In Vitro Comparison of Compressive and Tensile Strengths ofAcrylic Resins Reinforced by Silver Nanoparticles at $2 \%$ and $0.2 \%$ Concentrations. Journal of dental research, dental clinics, dental prospects. 2014;8(4):204.

[9] Philip JM, Rebecca LJ, Abraham HM, Venkatakrishnan C, Chandran CR, Anbuselvi S. Current trends in reducing microbial adhesion to acrylic denture base resins. Drug Invention Today. 2018;10(6).

[10] Lee J-H, Jo J-K, Kim D-A, Patel KD, Kim H-W, Lee H-H. Nano-graphene oxide incorporated into PMMA resin to prevent microbial adhesion. Dental Materials. 2018;34(4):e63-e72.

[11] Lara-Jara NU, Romo-Ramírez GF, del Pilar Goldaracena-Azuara M, Aragón-Piña A, Girón CB-T, Méndez-González MV, et al. Effect of Polishing Procedure on the Roughness and Bacterial Adhesion of Provisional Restorative Materials. 2018.

[12] WHO, world health organization., https://www.who.int/news-room/factsheets/detail/oral-health, 29/1/2019

[13] Simón-Soro A, Mira A. Solving the etiology of dental caries. Trends in microbiology. 2015;23(2):76-82.

[14] Lopes MB, Yan Z, Consani S, Gonini Júnior A, Aleixo A, McCabe JF. Evaluation of the coefficient of thermal expansion of human and bovine dentin by thermomechanical analysis. Brazilian dental journal. 2012;23(1):03-7.

[15] Sakaguchi R, Powers J. Craig's Restorative Dental Materials. 2012.

[16] Ellis SN, Romao CP, White MA. Near-Zero Thermal Expansion in FreezeCast Composite Materials. Ceramics. 2019;2(1):112-25.

[17] Jin J, Zhang L, Shi M, Zhang Y, Wang Q. Ti-GO-Ag nanocomposite: The effect of content level on the antimicrobial activity and cytotoxicity. International journal of nanomedicine. 2017;12:4209.

[18] Dong H, Qi S. Realising the Potential of Graphene-Based Materials for Biosurfaces-A Future Perspective. 2015.

[19] Mangadlao J, Santos C, Felipe M, de Leon A, Rodriguesb D, Advincula R. On the antibacterial mechanism of graphene oxide (GO) Langmuir-Blodgett films1. Chem Commun. 2015;51:2886-9.

[20] Gao Y, Wu J, Ren X, Tan X, Hayat T, Alsaedi A, et al. Impact of graphene oxide on the antibacterial activity of antibiotics against bacteria. Environmental Science: Nano. 2017;4(5):1016-24.

[21] Nanda SS, Yi DK, Kim K. Study of antibacterial mechanism of graphene oxide using Raman spectroscopy. Scientific reports. 2016;6:28443.

[22] He J, Zhu X, Qi Z, Wang L, Aldalbahi A, Shi J, et al. The Inhibition Effect of Graphene Oxide Nanosheets on the Development of Streptococcus mutans Biofilms. Particle \& Particle Systems Characterization. 2017;34(5):1700001.

[23] Morimune S, Nishino T, Goto T. PREPARATION OF GRAPHENE OXIDE REINFORCED POLY (METHYL METHACRYLATE)

[24] Pham VH, Dang TT, Hur SH, Kim EJ, Chung JS. Highly conductive poly (methyl methacrylate)(PMMA)-reduced graphene oxide composite prepared by self-assembly of PMMA latex and graphene oxide through electrostatic interaction. ACS applied materials \& interfaces. 2012;4(5):2630-6.

[25] Kee S, Munusamy Y, Ong K, Lai K. Effect of Preparation Methods on the Tensile, Morphology and Solar Energy Conversion Efficiency of RGO/PMMA Nanocomposites. Polymers. 2017;9(6):230.

[26] Edition ASN, editor. CLSI document M07-A92012.

[27] Deyab MH, Awady BE, Bakir NG. Is immersion in mint oil or apple vinegar solution a valid antifungal approach for acrylic soft liners? Future Dental Journal. 2018;4(2):302-7.

[28] Shah R, Kausar A, Muhammad B, Shah S. Progression from graphene and graphene oxide to high performance polymer-based nanocomposite: A review. Polymer-Plastics Technology and Engineering. 2015;54(2):173-83.

[29] Paz E, Forriol F, Del Real J, Dunne N. Graphene oxide versus graphene for optimisation of PMMA bone cement for orthopaedic applications. Materials Science and Engineering: C. 2017;77:1003-11.
[30] Khan AA, Mirza EH, Mohamed BA, Alharthi NH, Abdo HS, Javed R, et al. Physical, mechanical, chemical and thermal properties of nanoscale graphene oxide-poly methylmethacrylate composites. Journal of Composite Materials. 2018;52(20):2803-13.

[31] Ge Z, Yang L, Xiao F, Wu Y, Yu T, Chen J, et al. Graphene Family Nanomaterials: Properties and Potential Applications in Dentistry. International journal of biomaterials. 2018;2018.

[32] Falsetta ML, Klein MI, Colonne PM, Scott-Anne K, Gregoire S, Pai C-H, et al. Symbiotic relationship between Streptococcus mutans and Candida albicans synergizes virulence of plaque biofilms in vivo. Infection and immunity. 2014;82(5):1968-81.

[33] Zanni E, Chandraiahgari C, De Bellis G, Montereali M, Armiento G, Ballirano $\mathrm{P}$, et al. Zinc oxide nanorods-decorated graphene nanoplatelets: a promising antimicrobial agent against the cariogenic bacterium Streptococcus mutans. Nanomaterials. 2016;6(10):179.

[34] Khalili H, Sisakhtpour R, Abdollahzadeh S. Identification of biofilm producing bacterial species causing dental caries and their sensitivity to zoocin A and clove hydroalcoholic extract. Immunopathologia Persa. 2018;4(2).

[35] de Castro RD, Mota ACLG, de Oliveira Lima E, Batista AUD, de Araújo Oliveira J, Cavalcanti AL. Use of alcohol vinegar in the inhibition of Candida spp. and its effect on the physical properties of acrylic resins. BMC oral health. 2015;15(1):52.

[36] Wang Y, Zhang B, Zhai G. The effect of incubation conditions on the hemolytic properties of unmodified graphene oxide with various concentrations. RSC Advances. 2016;6(72):68322-34

[37] Balouiri M, Sadiki M, Ibnsouda SK. Methods for in vitro evaluating antimicrobial activity: A review. Journal of pharmaceutical analysis. 2016;6(2):71-9.

[38] Ghahremanloo A, Movahedzadeh M. The Effect of Silver Nano Particles on Candida Albicans and Streptococcus Mutans in Denture Acrylic Resins. Journal of Dental Materials \& Techniques. 2016;5(1).

[39] Alayande AB, Chae S, Kim IS. Surface morphology-dependent spontaneous bacterial behaviors on graphene oxide membranes. Separation and Purification Technology. 2019;226:68-74.

[40] Guazzo R, Gardin C, Bellin G, Sbricoli L, Ferroni L, Ludovichetti F, et al. Graphene-based nanomaterials for tissue engineering in the dental field. Nanomaterials. 2018;8(5):349.

[41] Safi IN. Evaluation the effect of nano-fillers (TiO2, AL2O3, SiO2) addition on glass transition temperature, E-Moudulus and coefficient of thermal expansion of acrylic denture base material. Journal of Baghdad College of Dentistry. 2014;325(2212):1-10. 